\title{
Transient exposure to elevated glucose levels causes persistent changes in dermal microvascular endothelial cell responses to injury
}

\author{
Qiuyun Wang ${ }^{1}$, Fei Song ${ }^{2}$, Jiaoyun Dong ${ }^{2}$, Liang Qiao ${ }^{3}$ \\ ${ }^{1}$ Department of Anesthesiology, Ruijin Hospital, Shanghai Jiaotong University School of Medicine, Shanghai, China; ${ }^{2}$ Burn Institute, Ruijin \\ Hospital, Shanghai Jiaotong University School of Medicine, Shanghai, China; ${ }^{3}$ Department of Burn and Plastic Surgery, Ruijin Hospital, Shanghai \\ Jiaotong University School of Medicine, Shanghai, China \\ Contributions: (I) Conception and design: L Qiao, Q Wang; (II) Administrative support: L Qiao; (III) Provision of study materials or patients: L Qiao, \\ Q Wang; (IV) Collection and assembly of data: Q Wang; (V) Data analysis and interpretation: Q Wang, F Song, J Dong; (VI) Manuscript writing: All \\ authors; (VII) Final approval of manuscript: All authors. \\ Correspondence to: Liang Qiao, MD. Department of burn and plastic surgery, Ruijin Hospital, Shanghai Jiaotong University School of Medicine, 197 \\ Ruijin Er Road, Shanghai 200025, China. Email: QL10727@rjh.com.cn.
}

\begin{abstract}
Background: The purpose of this study was to determine whether elevated glucose can induce a dermal microvascular endothelial cell metabolic memory, thus affecting angiogenesis in the repair process of mammalian cutaneous wound. We hypothesized that transient elevated glucose levels cause sustained alteration of endothelial cell responses to injury and persistent epigenetic changes in gene expression.

Methods: Human dermal microvascular endothelial cells were exposed to experimental conditions with or without $30 \mathrm{mM}$ D-glucose. The control group was maintained at $5 \mathrm{mM} \mathrm{D}$-glucose; while in the transient glucose group, after being exposed to $30 \mathrm{mM}$ D-glucose for two days, then being put under the control conditions during the experiment. Besides, in the whole process of the experiment, the chronic glucose group was kept in the condition with $30 \mathrm{mM}$ D-glucose. Proliferation, migration, tube formation, gene expression and histone methylation were assessed for individual conditions.

Results: Transient elevated glucose caused sustained effects on endothelial cell migration, tube formation and TIMP3 gene expression. The effects on TIMP3 expression were associated with persistent changes in histone modification at the 5' end of the TIMP3 gene, suggesting an epigenetic effect.

Conclusions: Hyperglycemia induced metabolic memory could promote the regulation of TIMP3, and it can be used as a possible innovative molecular target for therapeutic intervention in the treatment of chronic non-healing diabetic wounds.
\end{abstract}

Keywords: Diabetes; angiogenesis; hyperglycemia; metabolic memory; epigenetics

Submitted Nov 23, 2020. Accepted for publication Mar 10, 2021.

doi: $10.21037 /$ atm-20-7617

View this article at: http://dx.doi.org/10.21037/atm-20-7617

\section{Introduction}

Chronic non-healing wounds are a common and debilitating complication of type 2 diabetes mellitus (1). It is estimated that up to $25 \%$ of the diabetic population develop a nonhealing foot ulcer and an estimated $12 \%$ of individuals with diabetic foot ulcers require a surgical operation (2). On the basis of WHO's estimation, it was revealed that 347 million people suffer diabetes mellitus around the word (WHO/ ADA Fact sheet), and a global healthcare crisis is caused by the occurrence and prevalence of non-healing foot ulcers to some degree. Although non-healing diabetic ulcers have been strongly associated with underlying neuropathy (3), vascular insufficiency $(4,5)$ and tissue hypoxia $(6)$, the influence of hyperglycemia on the repair of the wound 
seems to be little known and little understood.

Hyperglycemia contributes to the development of diabetic complications in part by causing endothelial dysfunction and subsequent vascular injury (4). Unfortunately, some detrimental effects of hyperglycemia persist even after glucose levels have been normalized. Many large-scale clinical trials and animal models give convincing evidence for the support this phenomenon, which was commonly called as metabolic memory (7). The prospective Diabetes Control and Complications Trial and the ensuing follow-up Epidemiology of Diabetic Interventions and Complications study demonstrated that vascular complications develop and progress despite intensive insulin therapy after periods of hyperglycemia (8). Similar results have been observed in diabetic dogs and rats, with tight glycemic control in both species failing to prevent (9).

Emerging data suggest that hyperglycemia-induced metabolic memory is mediated by epigenetic regulation of gene expression (10). Epigenetic regulation changes the chromatin structure by histone methylation or acetylation and/or DNA methylation. In a diabetic rat model of metabolic memory, hyperglycemia induced epigenetic modifications at both the $\mathrm{SOD}_{2}$ and gene promoters that were maintained after return to normoglycemia $(11,12)$. In a zebrafish model of metabolic memory (13), hyperglycemia induced persistent changes in DNA methylation causing sustained effects on gene expression. Similarly, Transient exposure to hyperglycemia induced persistent epigenetic changes at the p65 gene in cultured macrovascular endothelial cells $(14,15)$. Collectively these studies implicate epigenetic regulation as an important mechanism for hyperglycemia-induced metabolic memory.

A literature search suggests that the only published study on contributions of hyperglycemia-induced metabolic memory on wound repair involved defects in wound closure and caudal fin regeneration in zebrafish which persisted after return to normoglycemia (16). Despite these promising results, the role of metabolic memory in mammalian wound repair has not been reported.

The study was aimed at finding out whether hyperglycemia can induce metabolic memory in human dermal microvascular endothelial cells and confirming the known participants in cutaneous angiogenesis during mammalian wound repair. We hypothesized that Transient hyperglycemia cause sustained effects on endothelial cell responses to injury and persistent epigenetic changes in gene expression.

The following article is presented in accordance with the
MDAR checklist (available at http://dx.doi.org/10.21037/ atm-20-7617).

\section{Methods}

\section{Cell culture}

Primary human adult dermal microvascular endothelial cells (HMVECad) were gained in a commercial manner (Life Technologies, Carlsbad, CA, USA) and cultured on tissue culture plastic, which was coated with Attachment Factor Protein (Life Technologies, Carlsbad, CA, USA) and kept constantly at $37^{\circ} \mathrm{C}$ and $5 \% \mathrm{CO}_{2}$ in Medium 131 supplemented with $5 \%$ Microvascular Growth Supplement, $100 \mathrm{U} / \mathrm{mL}$ penicillin and $100 \mathrm{mg} / \mathrm{mL}$ streptomycin (Life Technologies, Carlsbad, CA, USA). Two biological replicates (females aged 48 and 26 year old) were used for these studies with excellent reproducibility.

For all experiments, on study day -2 , dermal microvascular endothelial cells were seeded at $5 \times 10^{3}$ cells $/ \mathrm{cm}^{2}$ in medium 131, which contained $5 \mathrm{mM} \mathrm{D}$-glucose. While on day 0 , we exposed cells to experimental environment consisting of elevated levels of glucose $(30 \mathrm{mM}$ D-glucose; Life Technologies, Carlsbad, CA, USA) added to Medium 131; all experiments included three study groups of endothelial cells: Control, Transient glucose ,and Chronic glucose. The control group was kept constantly at $5 \mathrm{mM} \mathrm{D}$-glucose. While the Transient group was kept at a high-level glucose for two days, and then being put into Control Medium 131 conditions during experiment. The Chronic group was put into high glucose during the experiment. The another mannitol group was at $30 \mathrm{mM}$ mannitol as control for hyperosmolarity. Endothelial cell passage numbers 6-9 were used for all experiments. Experiments were performed with 4 6 replicates, with the repeated test at least 3 times.

\section{Cell proliferation assay}

Cell morphology and proliferation were assessed on days 0, 2 and 4. For morphology, cells were photographed using a Nikon Digital Sight Camera (DS-Fi1) and the camera was mounted on a Nikon TE300 inverted light microscope which was equipped with phase contrast objectives. Then images were imported into Adobe Photoshop $\mathrm{CS}^{\circledR}{ }^{\circledR}$ and a standard linear adjustment to brightness was applied to the entire image; no other adjustments to microscopic images were made. For cell proliferation, a Vicell Cell Viability Analyzer (Beckman Coulter, Brea, CA, USA) was used to 
count cells.

\section{Apoptosis assay}

The percentage of live, early apoptotic, late apoptotic and dead cells was confirmed by the use of the Muse ${ }^{\mathrm{TM}}$ Annexin V and Dead Cell Assay Kit (Millipore, Billerica, MA, USA) on days 0, 2 and 4. In brief, supernatant was collected and floating cells were pelleted and pooled with the pellet of trypsinized cells. The total cell pellet was resuspended in medium 131 and incubated with Annexin $\mathrm{V}$ reagent for 20 minutes at room temperature in the dark. And the cells were loaded onto the Muse ${ }^{\mathrm{TM}}$ Cell Analyzer to separate the live, early apoptotic, late apoptotic and dead cells.

\section{Scratch wound closure assay}

The influence of elevated glucose levels on endothelial cell migration was measured by the use of a scratch wound closure assay as previously described (17). In brief, cells were seeded at $5 \times 10^{4}$ cells/well in a 6-well plate and grown to confluence. The day of confluence was defined as day 0 for the Glucose treatment. On day 2, the scratch wound was created using sterile p200 pipette tip. Images were acquired with Nikon Eclipse TE300 along the scratch guidelines within the original three circles at multiple areas at the different timepoint (prior to scratch wound, immediately after scratch wound, and every $24 \mathrm{~h}$ before the wound confluent). All the images saved as TIFF files and imported into Adobe Photoshop CS3 to measure the remaining defect in the cell layer. Image analysis plugin Fovea Pro version 4.0 (Reindeer Graphics, Asheville, NC, USA) was used to measure the cell free space and the perimeter of each scratch wound. For each time point, they were normalized to the area of the original day 0 scratch defect. All data were shown as percent scratch wound closed. Images were acquired with Nikon Eclipse TE300 along the scratch guidelines within the original three circles at multiple areas at the different timepoint (prior to scratch wound, immediately after scratch wound, and every $24 \mathrm{~h}$ before the wound confluent). All the images saved as TIFF files and imported into Adobe Photoshop CS3 to measure the remaining defect in the cell layer. Image analysis plugin Fovea Pro version 4.0 (Reindeer Graphics, Asheville, NC, USA) was used to measure the cell free space and the perimeter of each scratch wound. For each time point, they were normalized to the area of the original day 0 scratch defect. All data were shown as percent scratch wound closed. For each time point, they were normalized to the area of the original day 0 scratch defect. All data were shown as percent scratch wound closed.

\section{Tube formation assay}

Microvascular endothelial cells were seeded into Matrigel ${ }^{\mathrm{TM}}$ (BD Biosciences, Bedford, MA, USA) on day 4 in the process of tube formation assay. Phase contrast images $(4 \times$ magnification) were taken in the center of each well of 6-well plateafter 24 hours in the Matrigel ${ }^{\mathrm{TM}}$ using a Nikon Eclipse TE300 inverted microscope which is equipped with a QImaging QICAM Monochrome Fast 1394 c12-bit cooled camera. Digital images were generated as TIFF files and imported into Adobe Photoshop CS3 containing the plugin FoveaPro version 4.0 (Reindeer Graphics, Asheville, NC, USA). Images were converted to a black and white binary image and skeletonized in order to determine total branch points and total line length, which are both accepted measures of tube formation (18).

\section{RNA extraction, $c D N A$ synthesis and real time PCR}

RNA was extracted from the dermal microvascular endothelial cells by the use of Trizol Reagent (Invitrogen, Carlsbad, CA, USA), and then the purification with the PureLink RNA Mini Kit (Life Technologies, Grand Island, NY, USA) was carried out, in which a DNase digestion step was included. By the use of an Omniscript RT kit (Qiagen, Valencia, CA, USA), cDNA was synthesized. Real time PCR using customized Primers (Table 1) was performed in a $\mathrm{ViiA}^{\mathrm{TM}} 7$ instrument (Applied Biosystems, Foster City, CA, USA) using Quantitect SYBR green PCR kit (Qiagen, Valencia, CA). The comparative $C_{t}$ method $\left(2^{-\Delta \Delta C t}\right)$ was selected for the qualification of gene expression levels, which were normalized to the housekeeping gene $\beta$-actin, ACTB; GFA had no notable influence on ACTB cycle threshold in the microvascular endothelial cells.

\section{Matrix ChIP assay}

Sample preparation and chromatin immuno-precipitation were done as previously described (19). Cells were fixed on day 4 with $1 \%$ formaldehyde for 10 minutes followed by quenching with $125 \mathrm{mM}$ Glycine for 5 minutes at room temperature. Cells were washed with PBS, mechanically harvested, spun down at 1,600 $\times \mathrm{g}$ for 5 minutes, washed with $1 \mathrm{~mL}$ PBS, spun down again and stored at $-80{ }^{\circ} \mathrm{C}$ as pellets. The pellet was 
Table 1 Primers for ChIP and RT-PCR

\begin{tabular}{ll}
\hline Variable & Sequence \\
\hline Human TIMP-3, Exon 1 (ChIP \& RTPCR) & \\
Forward & CAGTCATGTCCAACCCAGAA \\
Reverse & GGACATCCATGAATGCACAG \\
Human TIMP-3, Exon 5 (ChIP \& RTPCR) & \\
Forward & TCCTTTGGGCATCTCTTCTG \\
Reverse & GGGTTCGAGATCTCTTGTTGG \\
Human ACTB, Ex4-Ex5 (ChIP) & \\
Forward & AGAGCTACGAGCTGCCTGAC \\
Reverse & AAGGTAGTTTCGTGGATGCC \\
Human ACTB (RTPCR) & \\
Forward & CTGGAACGGTGAAGGTGACA \\
Reverse & AAGGGACTTCCTGTAACAATGCA \\
\hline
\end{tabular}

resuspended in $100 \mu \mathrm{L}$ of immunoprecipitation (IP) buffer (20 mM Tris- $\mathrm{HCl}, 150 \mathrm{mM} \mathrm{NaCl}, 1 \mathrm{mM}$ EDTA, 1\% Triton $\mathrm{X}-100,0.5 \mathrm{mM}$ PMSF, pH 7.5). The chromatin was sheared using a Bioruptor sonicator (Diagenode, Philadelphia, PA, USA) with $30 \mathrm{~s}$ on-off cycles for 15 minutes at high intensity on ice. Lysates were cleared by centrifugation at $10,000 \times \mathrm{g}$ at $4^{\circ} \mathrm{C}$ for 10 minutes.

In the Matrix ChIP assay, we used UV-treated polypropylene 96-well plates coated with $0.5 \mu \mathrm{g}$ protein A in $100 \mu \mathrm{L}$ PBS per well. After a wash with $100 \mu \mathrm{L}$ PBS per well, the wells were blocked with $200 \mu \mathrm{L}$ blocking buffer (IP buffer supplemented with $5 \%$ BSA and $0.1 \mathrm{mg} / \mathrm{mL}$ salmon sperm DNA) for 30 minutes at room temperature. Blocking buffer was aspirated and the wells were incubated with $0.25 \mu \mathrm{g}$ antibody in $100 \mu \mathrm{L}$ of blocking buffer per well for 60 minutes at room temperature. The below components are included in primary antibodies: rabbit anti-human H3K4m3 (Thermo Fisher Scientific, Waltham, MA, USA), mouse anti-human H3K27m3 (ab6002, Abcam, Cambridge, MA, USA) and rabbit anti-human H3 (ab1791, Abcam, Cambridge, MA, USA). Wells were cleared and chromatin samples (equivalent of 50,000 cells in $100 \mu \mathrm{L}$ of blocking buffer) were added to wells $(100 \mu \mathrm{L} /$ well $)$ and plates were floated in ultrasonic water bath for 60 minutes, $4^{\circ} \mathrm{C}$. Wells were washed three times with $100 \mu \mathrm{L}$ ice-cold IP buffer and once with $100 \mu \mathrm{L}$ ice cold TE buffer ( $\mathrm{pH}$ 7.5). Wells were incubated with $100 \mu \mathrm{L}$ elution buffer $(20 \mathrm{mM}$ Tris-base, $1 \mathrm{mM}$ EDTA, $0.1 \mathrm{mg} / \mathrm{mL}$ proteinase $\mathrm{K}$ ) for 15 minutes at $55^{\circ} \mathrm{C}$, and then it were stored for 10 minutes at $95^{\circ} \mathrm{C}$ in a thermocycler. Input DNA was purified in parallel by adding an aliquot of chromatin sample to $100 \mu \mathrm{L}$ of elution buffer. DNA samples were stored at $4{ }^{\circ} \mathrm{C}$. qPCR analysis of ChIP DNA samples was performed using primers listed in Table 1 . The reaction mixture was made of $2.5 \mu \mathrm{L} 2 \times$ SYBR Green PCR master mix (SensiMix ${ }^{\text {TM }}$ SYBR $^{\circledR} \mathrm{Hi}$-ROX Kit, Bioline USA Inc, Taunton, MA, USA), $0.25 \mu \mathrm{L}$ TIMP-3 specific primers (10 $\mu \mathrm{M}$ of each), $0.25 \mu \mathrm{L} \mathrm{H}_{2} \mathrm{O}$ and $2 \mu \mathrm{L}$ DNA sample in $5 \mu \mathrm{L}$ final volume in a 384-well optical reaction plate (Applied Biosystems, Foster City, CA, USA). Amplification (three steps, 40 cycles), data acquisition and analysis were carried out by the use of the 7900HT Real time PCR system (Applied Biosystems, Foster City, CA, USA). In each PCR run, dilutions of human genomic DNA were included that were used to generate standard curves for relative quantitation of qPCR. ChIP DNA data were normalized to input DNA and actin DNA, and were expressed as \% of actin DNA [(TIMP3/inputs)/(actin/inputs)].

\section{Statistical analyses}

All values are shown as a mean \pm standard deviation. We used the Student's $t$-test or ANOVA to find out the obvious statistical differences among in these groups, with $\mathrm{P}$ values less than or equal to 0.05 , which was considered as significant. A minimum of two biological replicates was analyzed for each end point. Each independent experiment 


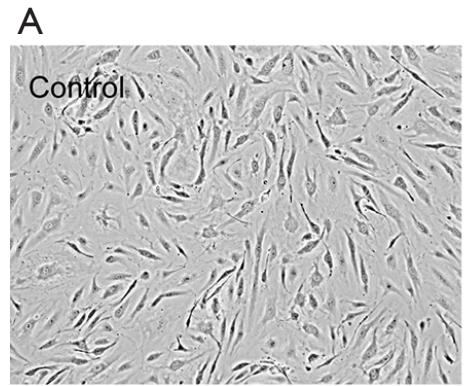

B

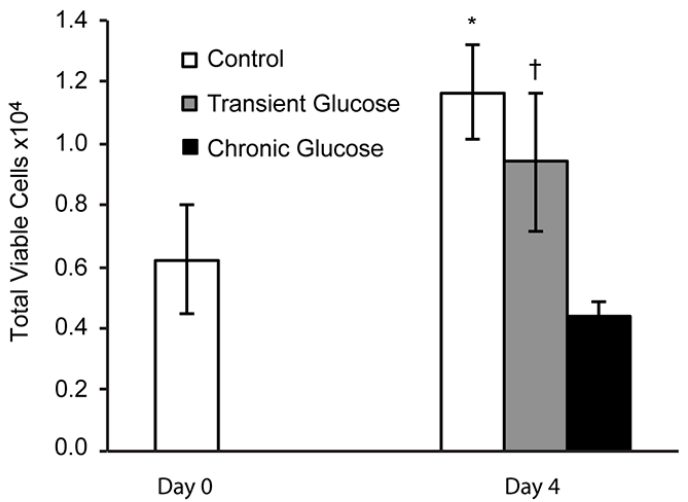

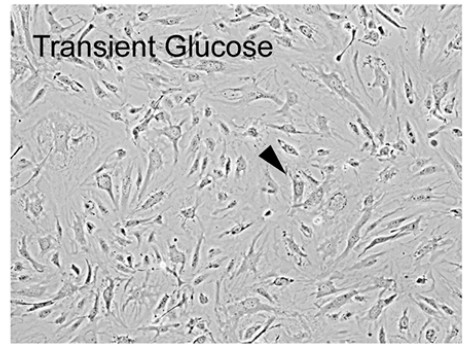

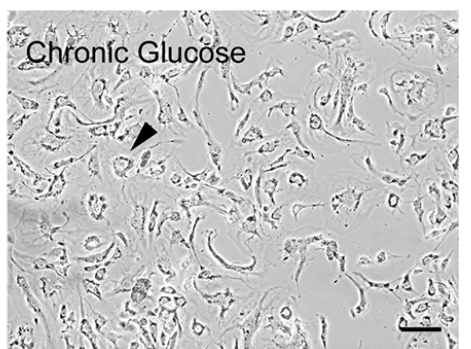

C

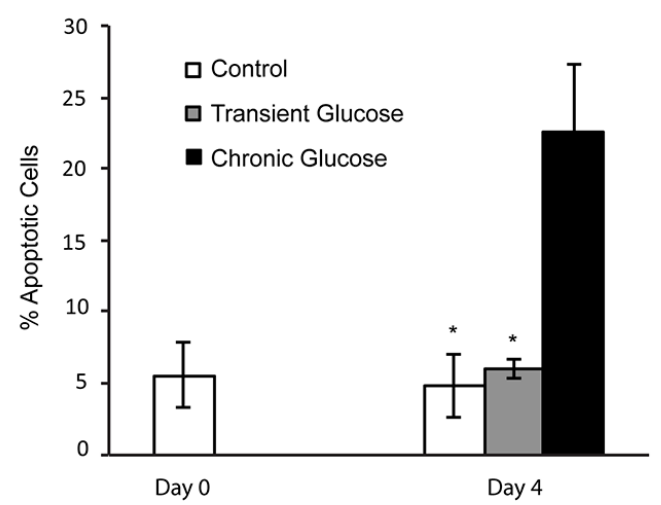

Figure 1 Transient glucose exposure showed sustained effects on morphology changes but not on cell viability of dermal microvascular endothelial cell. (A) Both cells treated in transient glucose and chronic glucose on day 4 shows lost spindle shape and appear in oval shape. The arrows show the fatty acid droplets accumulated in the nucleus (arrowhead). The magnification bar equals $50 \mu \mathrm{m}$. (B) Effects of Glucose on proliferation profile in dermal microvascular endothelial cell culture over time. ${ }^{*} \mathrm{P}<0.01$ vs. chronic $\mathrm{GFA},{ }^{\dagger} \mathrm{P}<0.05$ vs. chronic glucose. $(\mathrm{C})$ Effect of glucose on apoptosis of dermal microvascular endothelial cell over time. ${ }^{*} \mathrm{P}<0.01 v s$. chronic glucose. Data displayed indicate mean $\pm \mathrm{SD}$ of a single representative experiment with $\mathrm{N}=6$ for individual condition.

was performed with six wells under individual condition, with the repeated tests at least 3 times.

\section{Results}

\section{Effects of Glucose on dermal microvascular endothelial cell proliferation and viability}

To model metabolic memory in vitro, primary dermal microvascular endothelial cells were exposed to elevated levels of glucose for two days and then returned to physiological levels of glucose for a minimum of two days. Control cells were cultured in physiological levels of glucose, and Chronic group cells were exposed to elevated levels of glucose for the duration of the experiment.

We first investigated the effect of high glucose exposure on endothelial cell viability by examining cell morphology, cell proliferation and apoptosis (Figure 1). Cells exposed to high glucose treatment exhibited considerable altered morphology compared to controls (Figure 1A) and evidence of "fried egg" shaped cells with fatty acid droplets in the nucleus (Figure 1A, arrowhead). Whereas, these morphologic changes were most dramatic in the chronic group, they were also present in the Transient group. As a osmolarity control, cells exposed to mannitol treatment showed no changes in morphology compared to controls (Figure S1A). Despite this altered morphology, Transient Glucose had little to no effect on cell proliferation and total viable cell number compared to control after four days in culture (Figure 1B). There was also no significant increase in the percentage of apoptotic cells in the Transient Glucose group compared to the control (Figure 1C). In contrast, Chronic Glucose exposure induced endothelial cell apoptosis as evidenced by reduced viable cell number (Figure 1B) and a remarkable increase in the percentage of apoptotic cells (Figure 1C). Also, there were no significant changes of cell proliferation and apoptosis in mannitol treated group compare with the controls 
A
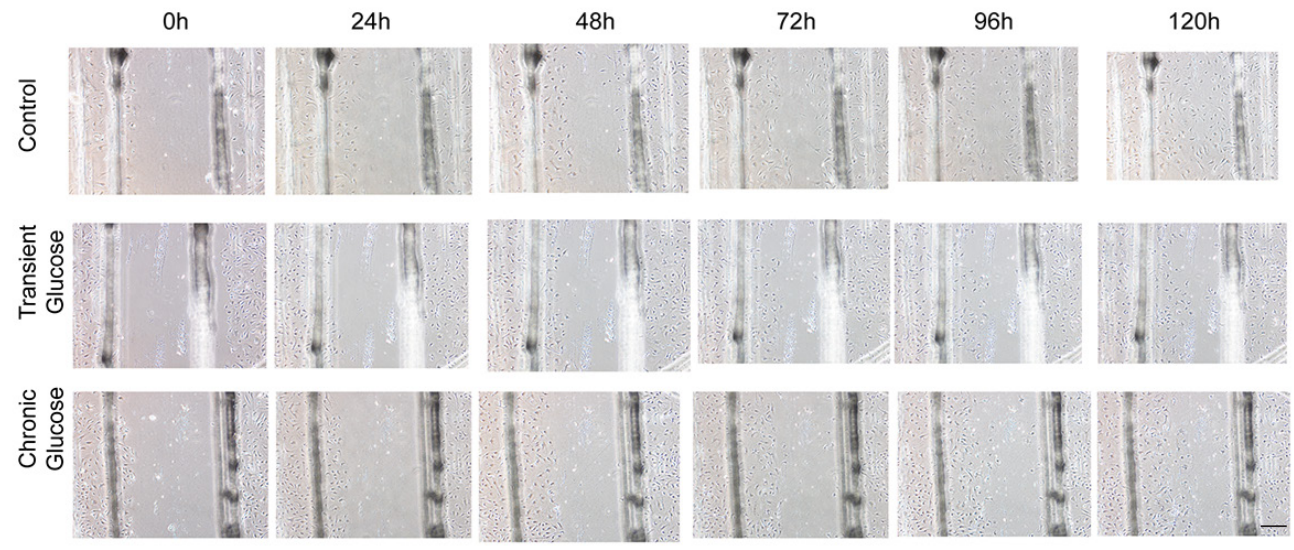

B

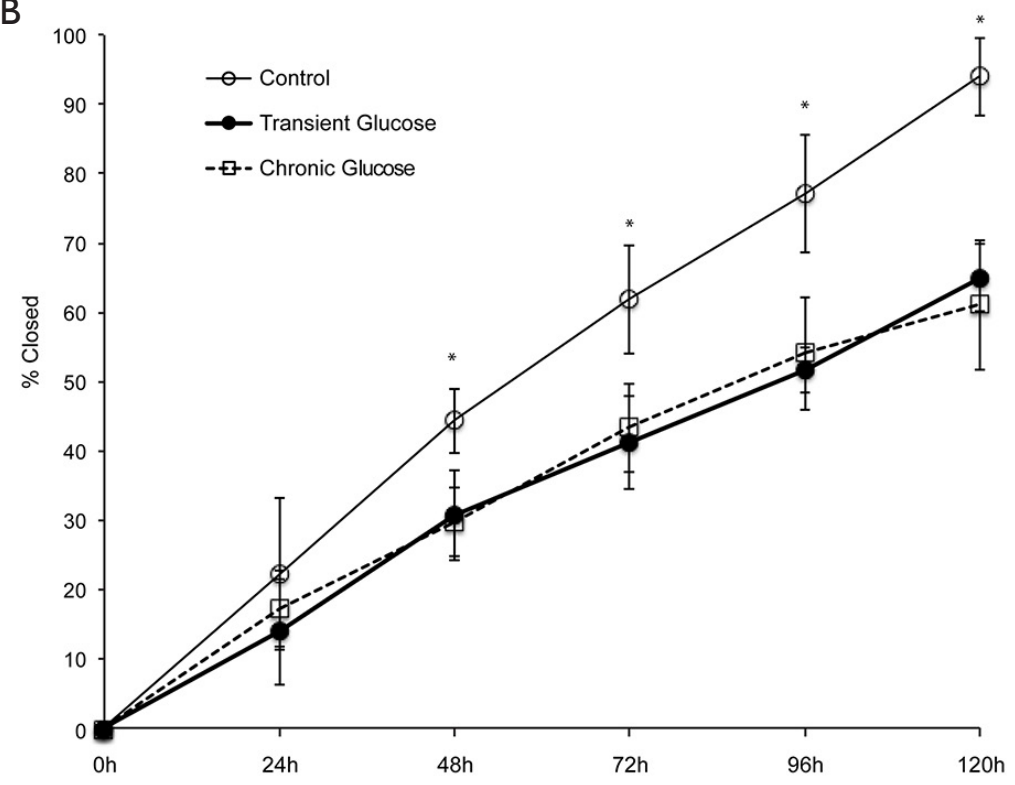

Figure 2 Transient glucose inhibit migration of dermal microvascular endothelial cells in a wound "scratch" assay. (A) Dermal microvascular endothelial cells were treated in M131 with or without elevated glucose and fatty acid for 2 days, and then scratched. The scratched cells were culture in conditional medium as follows: control group, continuous M131 without elevated glucose; transient glucose group, withdraw of elevated glucose and chronic glucose group, continuous M131 with elevated glucose. Images were captured immediately post scratch 0, 24, 48, 72, 96 and 120 h. (B) Transient elevated glucose and chronic glucose repressed notably the migration speed of human dermal microvascular endothelial cells at 48, 72, 96 and $120 \mathrm{~h}$ (all $* \mathrm{P}<0.05$ compared with transient glucose and chronic glucose group). Data displayed indicate mean $\pm \mathrm{SD}$ of a single representative experiment with $\mathrm{N}=6$ for individual condition. And the value of magnification bar is $200 \mu \mathrm{m}$.

(Figure S1B,C). Collectively these results suggest that transient glucose exposure had no sustained effects on microvascular endothelial cell viability.

\section{Effects of glucose exposure on dermal microvascular endothelial cell migration}

We found out the influence of Transient Glucose exposure on endothelial cell migration in a scratch wound assay
(Figure 2). Images of scratch defects at 48, 72, 96 and 120 hours after scratching show that Chronic Glucose cells exhibited a significant delay in scratch wound closure when it was in comparison with the control (Figure 2A). Quantification of the percentage of scratch wound closure provided the evidence that this delay has an important statistical meaning (Figure 2B). When compared with the chronic glucose cells, it can be found that transient glucose exposure showed the similar tendency, which also delayed 


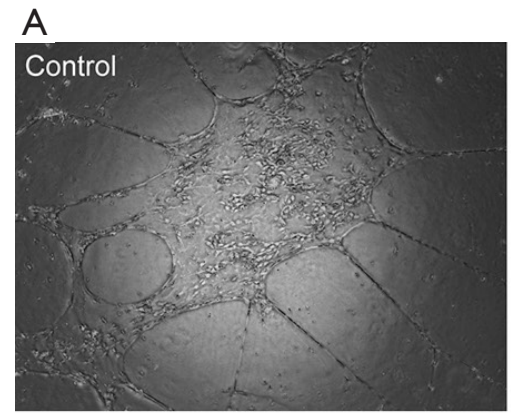

B

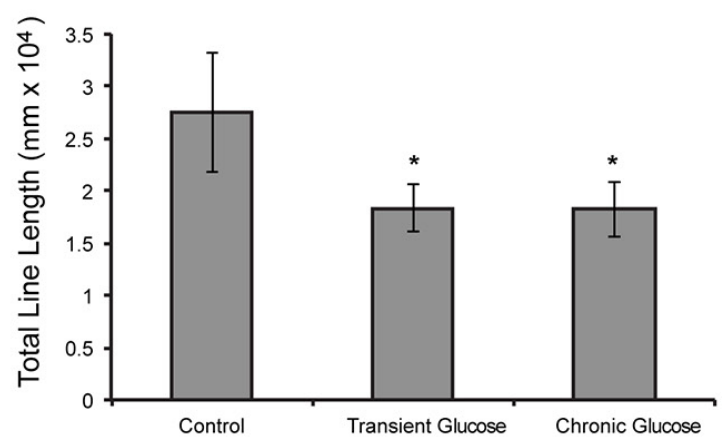

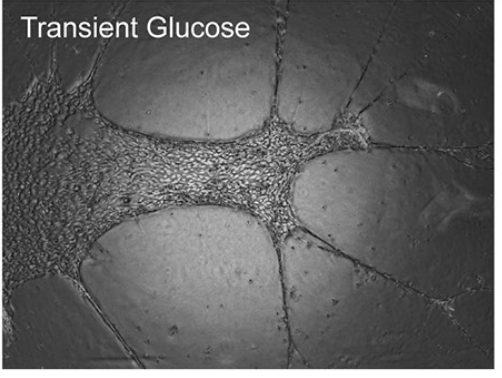

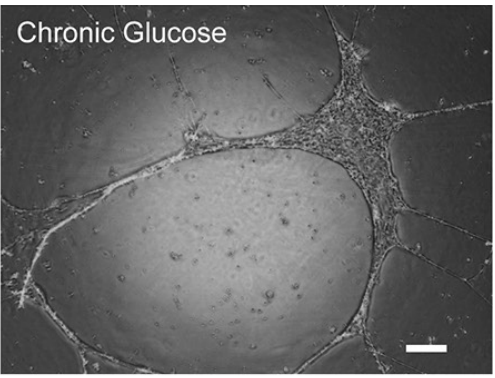

C

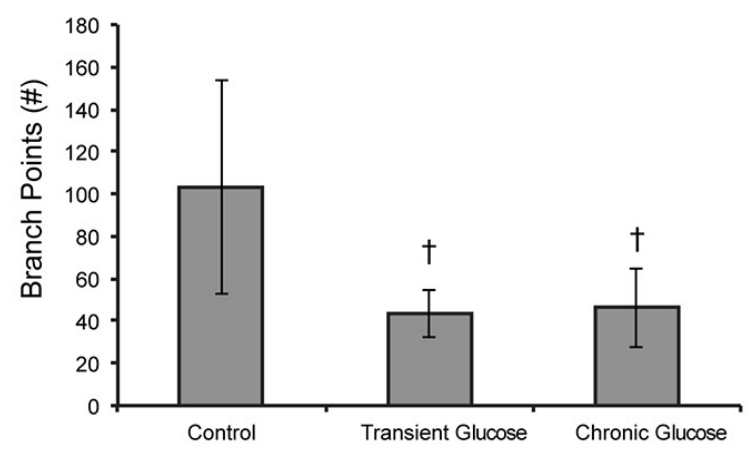

Figure 3 Transient glucose inhibit tube formation in dermal microvascular endothelial cells in vitro. (A) Tube formation assay was done as described in Methods. Cells were cultured for entire 24-h incubation period on matrigel. (B) Transient elevated glucose and (C) chronic glucose significantly reduced the total line length and branch point compared with control group. Error bars show $\mathrm{SD}$. ${ }^{*} \mathrm{P}<0.01,{ }^{\dagger} \mathrm{P}<0.05$ when compared with control. The magnification bar equals $50 \mu \mathrm{m}$.

endothelial cell migration into the scratch wound area, what's more, in the rate of endothelial migration between the transient and chronic glucose cells, no significant difference was found. The result also suggests that transient glucose exposure has a metabolic memory effect on endothelial cell migration. Also, there were no significant changes of cell migration in mannitol treated group compare with the controls (Figure S2).

\section{Effects of glucose exposure on endothelial tube formation}

Chronic glucose exposure decreased dermal microvascular endothelial cell tube formation when cultured on Matrigel $^{\mathrm{TM}}$ (Figure $3 A$ ) as evidenced by significantly reduced tube length (Figure $3 B$ ) and total number of branch points (Figure 3C) compared to control conditions. Likewise, transient glucose significantly reduced both tube length and total number of branch points. Again, there was no significant difference between the chronic glucose and transient glucose cellular responses. As a validated in vitro model of angiogenesis, these results suggest that transient exposure to elevated levels of glucose may impair angiogenesis during cutaneous wound repair.

\section{Effects of glucose exposure on TIMP3 gene expression}

We hypothesized that the sustained effects of transient glucose exposure on endothelial cell migration and tube formation were due in part to persistent changes in gene expression. We compared expression of 84 angiogenesisrelated genes among the control, transient glucose and chronic glucose groups using a commercially available PCR array (SABioSciences/Qiagen, Valencia, CA, USA). Only the TIMP3 gene showed changes in expression that persisted after return to physiological levels of glucose (data not shown). This result was confirmed by RT qPCR analysis of TIMP3 expression (Figure 4) using customized primers (Table 1). Similar to endothelial cells exposed to chronic glucose treatment, TIMP3 gene expression in endothelial cells in the transient glucose group was down-regulated compared to control treatment; TIMP3 expression levels were not notably different between the 
Page 8 of 11

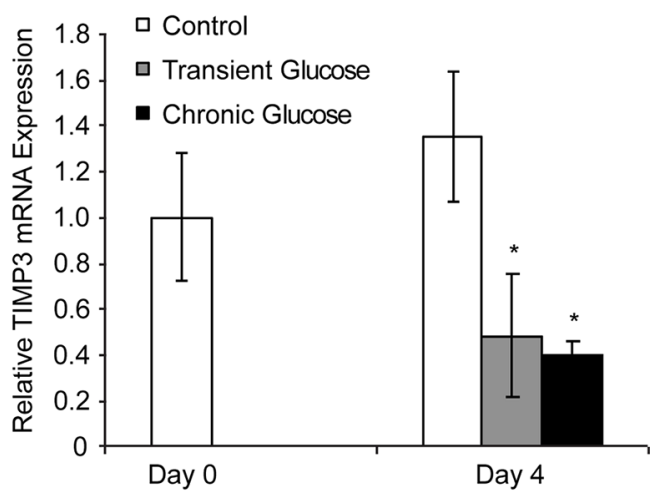

Figure 4 Transient elevated Glucose exposure induces a persistent change on Timp3 gene expression by dermal microvascular endothelial cell. Timp3 mRNA measured by RTPCR shows downregulated in both transient glucose group and chronic group $\left({ }^{*} \mathrm{P}<0.05\right.$ compared with control group on day 4$)$. There is no significant difference between control group on day 0 and day 4 . The Data displayed indicated mean \pm SD of a single representative experiment with $\mathrm{N}=6$ for individual condition.

transient and chronic glucose groups. Mannitol used as a control treatment to control for osmolarity had no notable influences on TIMP3 gene expression (Figure S3). These results suggest that transient Glucose exposure induces a persistent change in TIMP 3 gene expression by dermal microvascular endothelial cells that may be explained by chromatin or DNA modification.

\section{Glucose-induced epigenetic changes at the TIMP3 gene}

Using a chromatin immunoprecipitation assay (20), we examined glucose-induced changes in histone modifications at the TIMP3 gene. Specifically, we measured the density of $\mathrm{H} 3 \mathrm{~K} 27 \mathrm{~m} 3$ a histone modification associated with silenced genes and $\mathrm{H} 3 \mathrm{~K} 4 \mathrm{~m} 3$, a histone modification associated with transcribed genes (20) (Figure 5). Compared to the control treatment, glucose exposure significantly increased the density of the repressive marker, $\mathrm{H} 3 \mathrm{~K} 27 \mathrm{~m} 3$ and significantly decreased the density of the activating marker, $\mathrm{H} 3 \mathrm{~K} 4 \mathrm{~m} 3$ at the 5' end of the TIMP3 gene (exon 1). Glucose exposure did not change $\mathrm{H} 3 \mathrm{~K} 27 \mathrm{~m} 3$ and $\mathrm{H} 3 \mathrm{~K} 4 \mathrm{~m} 3$ levels at the 3 ' end of the gene (exon 5). There was no difference in density of histone modifications between the Transient and chronic glucose treatment groups. Glucose exposure had no significant effect on the density of either histone modification locus at the 5' end of the control housekeeping gene ACTB (exon 1). Collectively these results demonstrate
Wang et al. TIMP3 methylation affecting angiogenesis in diabetes
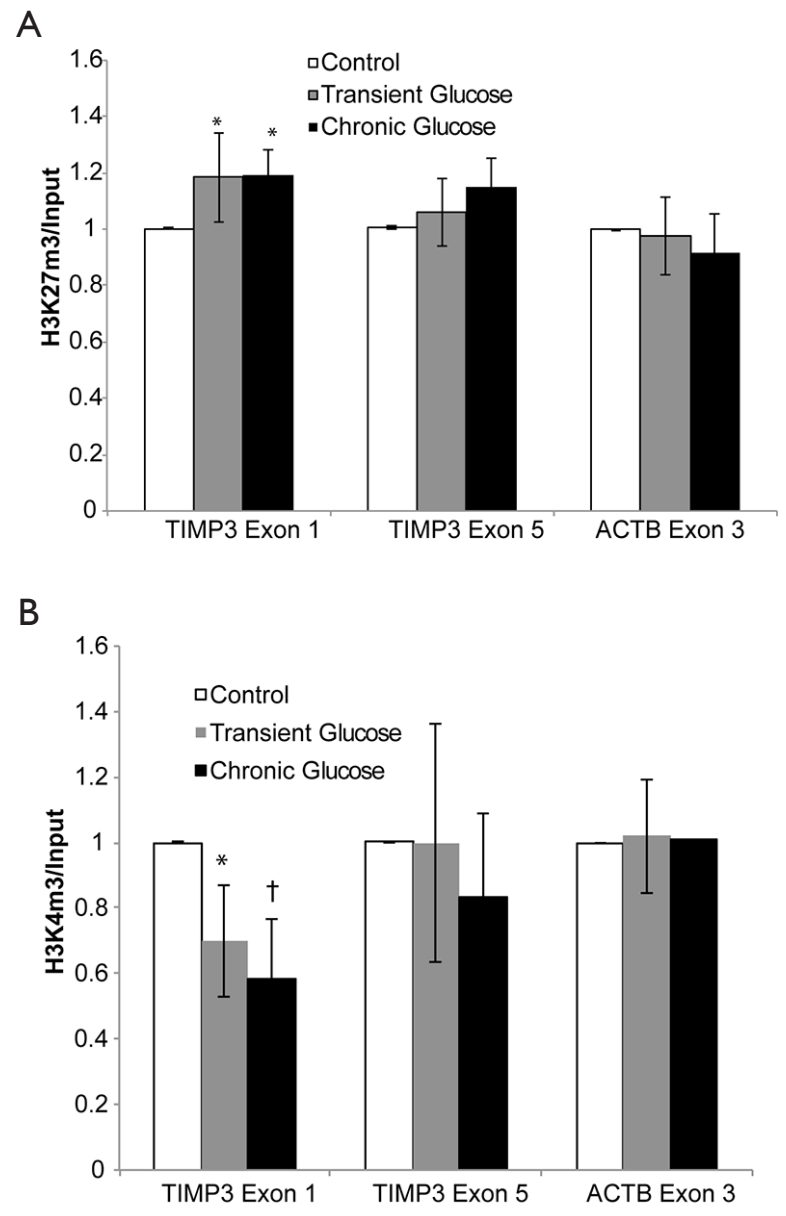

Figure 5 Transient exposure of elevated Glucose induces changes in histone modifications. ChIP analysis of histone $\mathrm{H} 3$ modification density at TIMP3 Exon 1 and Exon 5. Matrix ChIP was proceeded with antibodies to (A) $\mathrm{H} 3 \mathrm{~K} 4 \mathrm{~m} 3$ and (B) $\mathrm{H} 3 \mathrm{~K} 27 \mathrm{~m} 3$ as per summarized in the section of Method. Through the gene-specific primers (TIMP3 exon 1 and exon 5), the analysis of precipitated DNA completed by qPCR. After calculation, ChIP results are shown as fraction of input DNA. What's more, the results represent mean \pm SD. Signal ratios of PCR done in triplicate. *, $\mathrm{P}<0.05$ compared with control.

that the sustained effects on TIMP3 gene expression by transient exposure to elevated levels of glucose are related with alternations in histone modifications at the 5' end of the TIMP3 gene, which indicating an epigenetic effect.

\section{Discussion}

In response to cutaneous injury, dermal microvascular 
endothelial cells proliferate, migrate and differentiate to form new blood vessel sprouts from pre-existing vessels. To date, few publications have reported the effect of hyperglycemia on dermal microvascular endothelial cells (21) and wound angiogenesis (22). Moreover, in the available publications, exposure to high levels of glucose has been continuous. Data reported here are the first to demonstrate sustained effects of transient exposure to elevated levels of glucose on dermal microvascular endothelial cell migration, tube formation, TIMP3 gene expression and epigenetic changes at the 5' end of the TIMP3 gene. Collectively our findings are consistent with the hypothesis that transient exposure to hyperglycemia induces state of metabolic memory in dermal microvascular endothelial cells. Whereas previous studies have demonstrated that continuous exposure to high glucose levels inhibits dermal microvascular endothelial cell migration and tube formation (23), our data indicate that transiently elevated glucose induce persistent biological cellular responses after normalization of conditions, consistent with a metabolic memory.

Our observation that elevated levels of glucose reduce TIMP3 mRNA level in dermal microvascular endothelial cells is novel, as changes in TIMP3 expression in dermal microvascular endothelial cells have not been previously reported. In spite of strong evidence that TIMP3 regulates inflammation, angiogenesis and extracellular matrix remodeling (24), which are key responses to injury during cutaneous wound repair, there is scant information about TIMP3 expression in acute wounds (25). Previous published studies have focused on TIMP-1 and TIMP-2 expression in diabetic wounds $(26,27)$. However, in one recent publication, Menghini and colleagues reported reduced TIMP3 mRNA levels in ischemic wounds compared to neuropathic diabetic foot ulcers (28); a limitation of their study is that they did not compare TIMP3 in diabetic wounds to non-diabetic wounds. Hence the temporal and spatial contributions of TIMP3 to normal or dysfunctional wound repair processes is not well defined.

Our observation that down-regulation of TIMP3 mRNA after transient Glucose exposure is associated with persistently increased levels of the silencing mark $\mathrm{H} 3 \mathrm{~K} 27 \mathrm{~m} 3$ and decreased levels of the activation mark H3K4m3, supports our hypothesis that TIMP3 gene expression in microvascular endothelial cells is regulated by epigenetic factors involving chromatin modifications. Our results corroborate previous reports that $\mathrm{H} 3 \mathrm{~K} 27 \mathrm{~m} 3$ is associated with reduced TIMP3 transcription and $\mathrm{H} 3 \mathrm{~K} 4 \mathrm{me} 3$ is associated with increased TIMP3 expression in prostate (28) and ovarian cancer cell lines (29). The relevance of our observations is also supported by reports that hyperglycemia alters the density of the $\mathrm{H} 3 \mathrm{~K} 4 \mathrm{~m} 1, \mathrm{H} 3 \mathrm{~K} 9 \mathrm{~m} 2$ and $\mathrm{H} 3 \mathrm{~K} 9 \mathrm{~m} 3$ on the 65 gene in aortic endothelial cells, increased. H4K20m3 density on the SOD2 promoter in mouse retina (30) and decreased $\mathrm{H} 3 \mathrm{~K} 9 \mathrm{me} 3$ on the IL-6 gene in rat cardiomyocytes (31). All of these publications reported that the epigenetic change in histone methylation persisted after restoration of normoglycemic conditions.

The mechanism by which elevated glucose alter microvascular endothelial cellular biologic, genomic, and epigenetic responses warrants further analysis. One explanation that the observed changes result from hyperosmotic effect of glucose is unlikely given that an equal concentration of mannitol as a control for osmolarity did not alter the tested phenotypic responses. We have previously reported that elevated glucose causes oxidative responses including hydrogen peroxide production and that the responses could be attenuated with the antioxidants, alpha-tocopherol succinate and L-ascorbic acid (32). Studies have shown that hyperglycemia may induce apoptosis of vascular endothelial cells in vitro. In the study, transient glucose may also induce apoptosis of vascular endothelial cell, but more endothelial cells became apoptotic after persistent hyperglycemia. The impact of hyperglycemia on increasing the oxidative stress of endothelial cells has been confirmed. which might be ascribed to the long-term exposure to hyperglycemia used in this study. Therefore, it is possible that the epigenetic effects are caused by oxidative stress. Finally, TIMP3 has been previously reported to inhibit angiogenesis; as such, our results regarding changes in endothelial cell migration and tube formation as well as epigenetic effects on TIMP3 gene expression may be independent and may not represent an association between the endothelial cell biological responses and regulation of TIMP3 expression. Importantly, our results do indicate that a gene specific persistent alteration in epigenetic regulation is associated with transient exposure to hyperglycemia.

In summary, this novel report of metabolic memory in dermal microvascular endothelial cells indicated the effects of transiently elevated levels of glucose on angiogenesis, a critical stage of dermal wound repair. Transient exposure to elevated glucose levels had constant influence on endothelial cell migration, tube formation and TIMP3 expression. The Effects of glucose on TIMP3 gene expression were related with alternations in histone methylation that persisted after normalization of glucose levels. Overall, our results suggest that metabolic memory contributes to the impaired 


\section{Page 10 of 11}

neovascularization observed in chronic non-healing diabetic wounds and define potential molecular targets for therapeutic intervention.

\section{Acknowledgments}

Funding: This work was supported by the National Natural Science Fund of China (81272112). Thanks Dr. Nicole Gibran, Dr. Oleg Denisenko, Mrs Lara A Muffley and Dr. Anne M Hocking from University of Washington for research design and training.

\section{Footnote}

Reporting Checklist: The authors have completed the MDAR checklist. Available at http://dx.doi.org/10.21037/atm-207617

Data Sharing Statement: Available at http://dx.doi. org/10.21037/atm-20-7617

Conflicts of Interest: All authors have completed the ICMJE uniform disclosure form (available at http://dx.doi. org/10.21037/atm-20-7617). Dr. LQ reports grants from National Natural Science Fund (81272112), during the conduct of the study. The other authors have no conflicts of interest to declare.

Ethical Statement: The authors are accountable for all aspects of the work in ensuring that questions related to the accuracy or integrity of any part of the work are appropriately investigated and resolved. This project received an ethical exemption from the Ethics Committee of Ruijin Hospital.

Open Access Statement: This is an Open Access article distributed in accordance with the Creative Commons Attribution-NonCommercial-NoDerivs 4.0 International License (CC BY-NC-ND 4.0), which permits the noncommercial replication and distribution of the article with the strict proviso that no changes or edits are made and the original work is properly cited (including links to both the formal publication through the relevant DOI and the license). See: https://creativecommons.org/licenses/by-nc-nd/4.0/.

\section{References}

1. Arya AK, Pokharia D, Tripathi K. Relationship between
Wang et al. TIMP3 methylation affecting angiogenesis in diabetes

oxidative stress and apoptotic markers in lymphocytes of diabetic patients with chronic non healing wound. Diabetes Res Clin Pract 2011;94:377-84.

2. Sen CK, Gordillo GM, Roy S, et al. Human skin wounds: a major and snowballing threat to public health and the economy. Wound Repair Regen 2009;17:763-71.

3. Bönhof GJ, Herder C, Strom A, et al. Emerging Biomarkers, Tools, and Treatments for Diabetic Polyneuropathy. Endocr Rev 2019;40:153-92.

4. Aldana PC, Cartron AM, Khachemoune A. Reappraising Diabetic Foot Ulcers: A Focus on Mechanisms of Ulceration and Clinical Evaluation. Int J Low Extrem Wounds 2020:1534734620944514.

5. Segev R. Healing Tough Wounds Using Topical Oxygen Therapy During Hemodialysis Sessions. Nephrol Nurs J 2019;46:330-6.

6. Amin KN, Umapathy D, Anandharaj A, et al. miR-23c regulates wound healing by targeting stromal cell-derived factor-1alpha (SDF-1alpha/CXCL12) among patients with diabetic foot ulcer. Microvasc Res 2020;127:103924.

7. Roy S, Sala R, Cagliero E, et al. Overexpression of fibronectin induced by diabetes or high glucose: phenomenon with a memory. Proc Natl Acad Sci U S A 1990;87:404-8.

8. Kilpatrick ES, Rigby AS, Atkin SL. The Diabetes Control and Complications Trial: the gift that keeps giving. Nat Rev Endocrinol 2009;5:537-45.

9. Kowluru RA. Effect of reinstitution of good glycemic control on retinal oxidative stress and nitrative stress in diabetic rats. Diabetes 2003;52:818-23.

10. Ding GL, Huang HF. Role for tet in hyperglycemiainduced demethylation: a novel mechanism of diabetic metabolic memory. Diabetes 2014;63:2906-8.

11. Kowluru RA, Santos JM, Mishra M. Epigenetic modifications and diabetic retinopathy. Biomed Res Int 2013;2013:635284.

12. Mishra M, Zhong Q, Kowluru RA. Epigenetic modifications of Keap1 regulate its interaction with the protective factor Nrf2 in the development of diabetic retinopathy. Invest Ophthalmol Vis Sci 2014;55:7256-65.

13. Intine RV, Olsen AS, Sarras MP Jr. A zebrafish model of diabetes mellitus and metabolic memory. J Vis Exp 2013;(72):e50232.

14. El-Osta A, Brasacchio D, Yao D, et al. Transient high glucose causes persistent epigenetic changes and altered gene expression during subsequent normoglycemia. J Exp Med 2008;205:2409-17.

15. Brasacchio D, Okabe J, Tikellis C, et al. Hyperglycemia 
induces a dynamic cooperativity of histone methylase and demethylase enzymes associated with gene-activating epigenetic marks that coexist on the lysine tail. Diabetes 2009;58:1229-36.

16. Olsen AS, Sarras MP Jr, Intine RV. Limb regeneration is impaired in an adult zebrafish model of diabetes mellitus. Wound Repair Regen 2010;18:532-42.

17. Smith AN, Willis E, Chan V'T, et al. Mesenchymal stem cells induce dermal fibroblast responses to injury. Exp Cell Res 2010;316:48-54.

18. Muffley LA, Pan SC, Smith AN, et al. Differentiation state determines neural effects on microvascular endothelial cells. Exp Cell Res 2012;318:2085-93.

19. Flanagin S, Nelson JD, Castner DG, et al. Microplatebased chromatin immunoprecipitation method, Matrix ChIP: a platform to study signaling of complex genomic events. Nucleic Acids Res 2008;36:e17.

20. Denisenko O, Lin B, Louey S, et al. Maternal malnutrition and placental insufficiency induce global downregulation of gene expression in fetal kidneys. J Dev Orig Health Dis 2011;2:124-33.

21. Jain M, LoGerfo FW, Guthrie P, et al. Effect of hyperglycemia and neuropeptides on interleukin-8 expression and angiogenesis in dermal microvascular endothelial cells. J Vasc Surg 2011;53:1654-60.e2.

22. Wang L, Song D, Wei C, et al. Telocytes inhibited inflammatory factor expression and enhanced cell migration in LPS-induced skin wound healing models in vitro and in vivo. J Transl Med 2020;18:60.

23. Syeda MM, Jing X, Mirza RH, et al. Prostaglandin transporter modulates wound healing in diabetes by regulating prostaglandin-induced angiogenesis. Am J Pathol 2012;181:334-46.

24. Nawaito SA, Sahadevan P, Sahmi F, et al. Transcript levels

Cite this article as: Wang Q, Song F, Dong J, Qiao L. Transient exposure to elevated glucose levels causes persistent changes in dermal microvascular endothelial cell responses to injury. Ann Transl Med 2021;9(9):758. doi: 10.21037/atm-207617 for extracellular matrix proteins are altered in MK5deficient cardiac ventricular fibroblasts. J Mol Cell Cardiol 2019;132:164-77.

25. Yang X, Wang J, Guo SL, et al. miR-21 promotes keratinocyte migration and re-epithelialization during wound healing. Int J Biol Sci 2011;7:685-90.

26. Huang SM, Wu CS, Chiu MH, et al. High glucose environment induces M1 macrophage polarization that impairs keratinocyte migration via TNF-alpha: An important mechanism to delay the diabetic wound healing. J Dermatol Sci 2019;96:159-67.

27. Trøstrup H, Holstein P, Karlsmark T, et al. Uncontrolled gelatin degradation in non-healing chronic wounds. J Wound Care 2018;27:724-34.

28. Menghini R, Uccioli L, Vainieri E, et al. Expression of tissue inhibitor of metalloprotease 3 is reduced in ischemic but not neuropathic ulcers from patients with type 2 diabetes mellitus. Acta Diabetol 2013;50:907-10.

29. Deb G, Shankar E, Thakur VS, et al. Green tea-induced epigenetic reactivation of tissue inhibitor of matrix metalloproteinase-3 suppresses prostate cancer progression through histone-modifying enzymes. Mol Carcinog 2019;58:1194-207.

30. Kowluru RA, Santos JM, Zhong Q. Sirt1, a negative regulator of matrix metalloproteinase-9 in diabetic retinopathy. Invest Ophthalmol Vis Sci 2014;55:5653-60.

31. Gu Q, Kong Y, Yu ZB, et al. Hypoxia-induced SOCS3 is limiting STAT3 phosphorylation and NF-kappaB activation in congenital heart disease. Biochimie 2011;93:909-20.

32. Muangman P, Spenny ML, Tamura RN, et al. Fatty acids and glucose increase neutral endopeptidase activity in human microvascular endothelial cells. Shock 2003;19:508-12. 


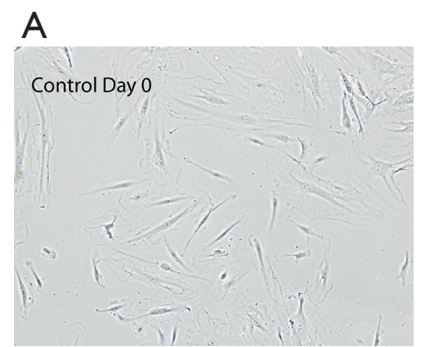

B

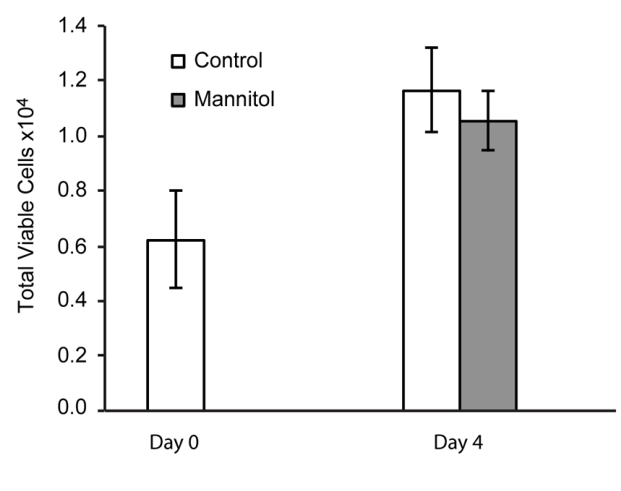

Mannitol

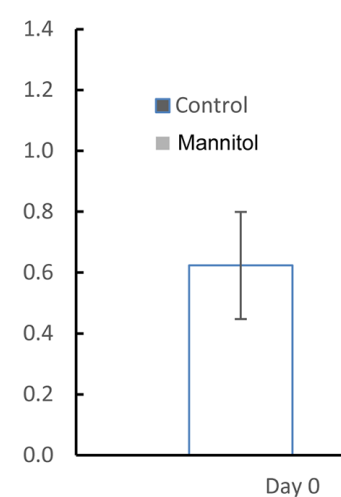

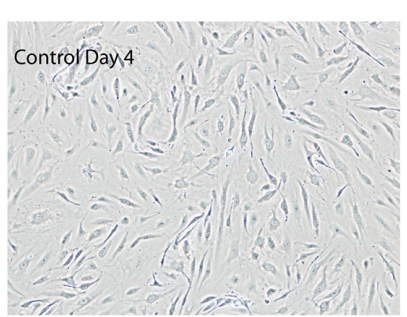

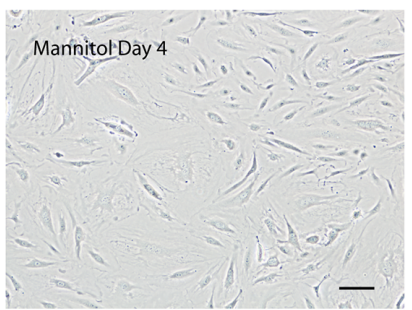

C

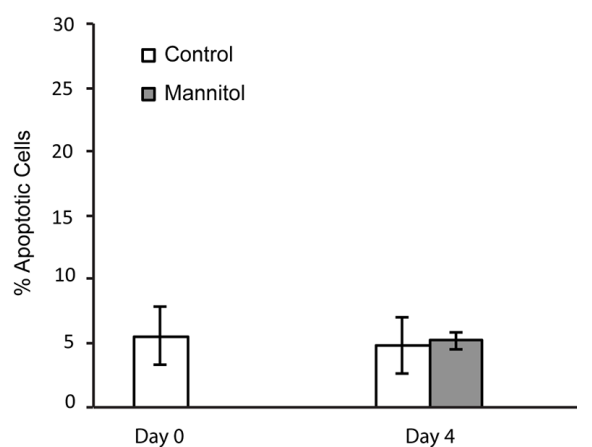

Figure S1 Mannitol exposure showed no effects on morphology changes and cell viability of dermal microvascular endothelial cell. (A) Both cells treated in mannitol transient on day 4 shows spindle shape and appear in oval shape. The magnification bar equals $50 \mu \mathrm{m}$. (B) Effects of mannitol on proliferation profile in dermal microvascular endothelial cell culture over time. (C) Effect of mannitol on apoptosis of dermal microvascular endothelial cell over time. 
A

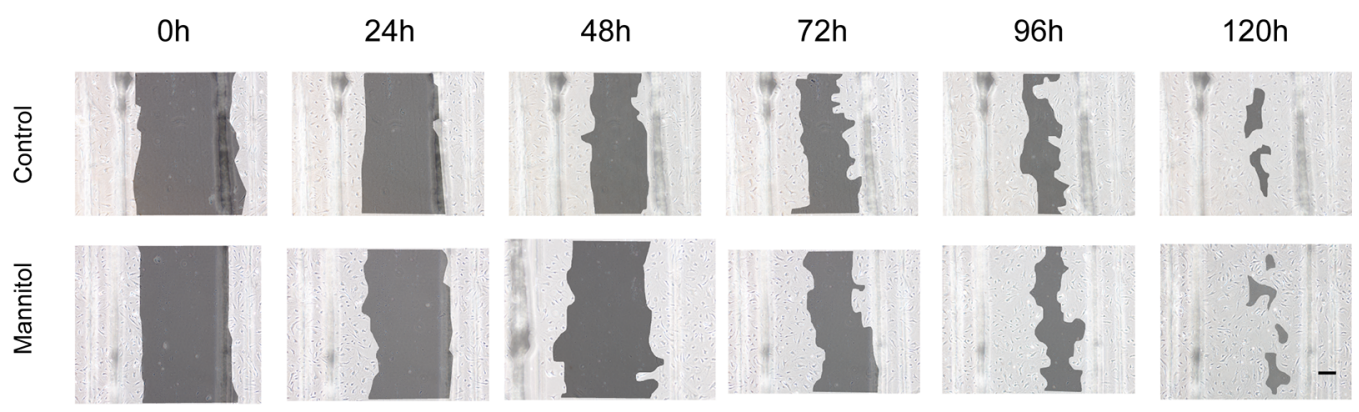

B

Effect of mannitol on cell migration

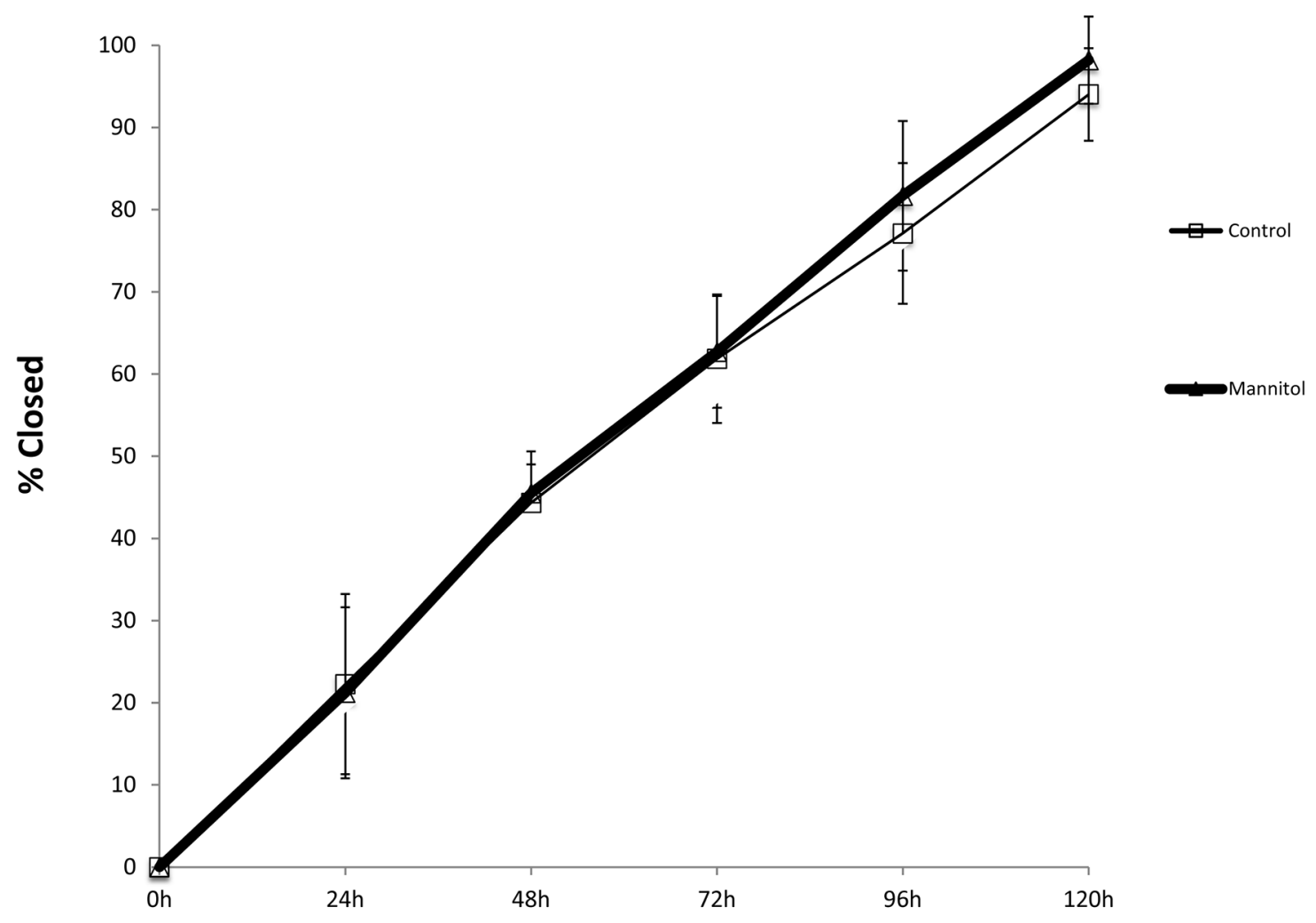

Figure S2 There are no significant difference between control and Mannitol group of dermal microvascular endothelial cells in a wound "scratch" assay. (A) Dermal microvascular endothelial cells were treated in M131 with or without elevated glucose and fatty acid for 2 days, and then scratched. The scratched cells were culture in conditional medium as follows: control Group, continuous M131 without elevated glucose; Mannitol Group, continuous M131 with elevated $30 \mathrm{mM}$ mannitol. Images were captured immediately post scratch 0, 24, 48, 72, 96 and 120 h. (B) Data displayed indicate mean \pm SD of a single representative experiment with $\mathrm{N}=6$ for individual condition. And the value of magnification bar is $200 \mu \mathrm{m}$. 


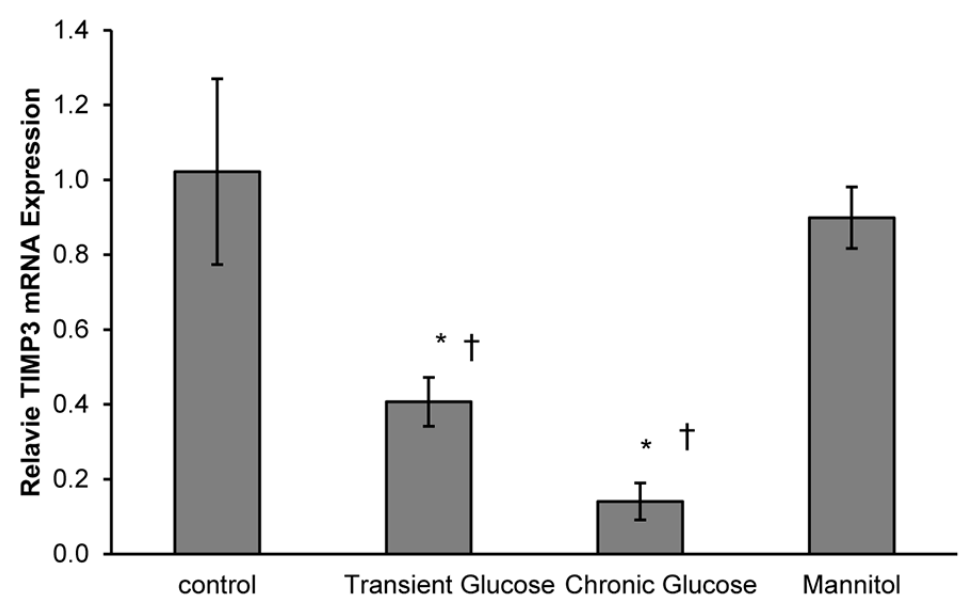

Figure S3 Transient elevated Glucose exposure induces a persistent change on Timp3 gene expression by dermal microvascular endothelial cell. Timp 3 mRNA measured by RTPCR shows down-regulated in both transient Glucose group and Chronic group $\left({ }^{*} \mathrm{P}<0.05\right.$ compared with control group on day 4). There is no significant difference between control group on day 0 and day 4 . Mannitol as a Control treatment to control for osmolarity did not affect TIMP3 gene expression significantly. The Data displayed indicated mean \pm SD of a single representative experiment with $\mathrm{N}=6$ for individual condition. 